\title{
On certain aftershock and foreshock parameters in the area of Greece
}

\author{
Basil C. PAPAZiChos (*)
}

Received on October $25 \overline{t h}, 1974$

Summary. - Published information (12) on the aftershocks and foreshocks of many principal shallow earthquakes occurred in the area of Greece between 1911 and 1973 constitutes a more or less homogeneous and complete sample of data in respect to some properties of these seismic sequences. These data have been used to determine certain parameters of these sequences.

The value of the decay parameter $p$, in the time distribution law of aftershocks, is independent of the magnitude range and varies between 0.7 and 1.9 in this area. The smallest value was found for the aftershock sequence of an earthquake believed to be associated with the Kremasta artificial lake, while the largest value was found for the aftershock sequence of an earthquake occurred in the voleanic part of the Hellenic arc. The probability, $N$, that the largest aftershock will occur $T_{1}$ days after the main shock or later is given by a relation of the form $N=c-k \log T_{1}$.

Representative values of the parameter $b$, in the frequeney-magnitude relation, have been found for the foreshocks as well as for the aftershocks of the same main shocks, by a proper grouping of the data. This value is equal to 0.67 for foreshocks and equal to 0.92 for the corresponding aftershocks. The difference in magnitude between the main shock and the largest aftershock is almost independent of the magnitude of the main shock. The relation $M_{0}-i_{i}=1.1$ holds on an average.

Riassunto. - Informazioni (12) pubblicate sulle repliche e scosse premonitrici di molti importanti terremoti superficiali avvenuti nellarea della

$\left(^{*}\right)$ National Observatory of Atlens, Seismological Institute, Athens. Greece. 
Grecia fra il 1911 ed il 1973 , costituiseono un esempio più o meno omogeneo e completo di dati cirea alcune proprieti di queste sequenze sismiche.

11 valore del decadimento del parametro $p$, nella legre della distribuzione nel tempo di repliche, è indipendente dalla variazione della magnitudo ed i suoi valori sono compresi, in questa zona, fra 0.7 e 1.9 . 11 valore più piceolo è stato trovato por la secpuenza dolle repliche di un terremoto che si è ritenuto associato al lago artificiale di Kremasta, mentre il più grande fu trovato per la sequenza delle repliche di un terremoto avvenuto nella parte vuleanica dell'areo ellenico. Ial probabilita $X$ che la replica magriore avverà $T_{1}$ o più griorni dopo la seossa principale è clata dalla relazione $N=c-k \log T_{1}$.

Valori significativi per il parametro $b$, nella relazione frequenzamagnitudo, somo stati trovati e per le premonitriei e per le repliche della medesima seossa principale, raggruppando i dati in modo appropriato. Questo valore de di 0.67 per le premonitriei e di 0.92 per le corrispondenti repliche. La differenza in magnitudo fra la scossa principale e le repliche più forti è pressoche indipendente dalla magnitudo della scossa principale.

Ia relazione $I_{0} \rightarrow I_{1}=1.1$, mediamente, resta valida.

\section{INTRODUCTION}

Research on several properties of seismic sequences has been carried out for several decales but this research has been much intensified during the last two decales. The interest of seismologists in such a kind of research is due to the fact that statistical and other properties of the seismic sequences are related to several important seismological problems. Such problems are the earthquake prediction, the identification of artificial events and the stress and the mechanical conditions of the material in the focal regions.

The first attempt to investigate properties of the seismic sequences in Greece and the surrounding area has been made by the present author and his colleagues $\left(^{6}\right)$. Since then several other papers have been published on this subject $(1,2,7)$. This area is bounder by the $34^{\circ} \mathrm{N}$ and $42^{\circ} \mathrm{N}$ parallels and by the $19^{\circ} \mathrm{E}$ and $29^{\circ} \mathrm{E}$ meridians.

Information on the origin times and magnitudes of aftershocks and foreshocks of all the main shallow shocks $(=177)$ with $M_{0} \geqslant 5.6$ which occurred in the area of Greece between 1911 and 1973, and such information on the aftershocks and foreshocks of all the main shallow shocks $(=46)$ with $5.1 \leqslant M_{0} \leqslant 5.5$ which occurred in the same area between 1966 and 1973 have been published by the present author 
and his colleagues $(1,2,3)$. These two samples of data can be considered homogeneous and complete, and are used to determine certain properties of the seismic sequences in the area of Greece.

Figure 1 is an index map of the locations of the epicenters of all the main shocks with $M_{0} \geqslant 5.6$, which occurred in the area of Greece

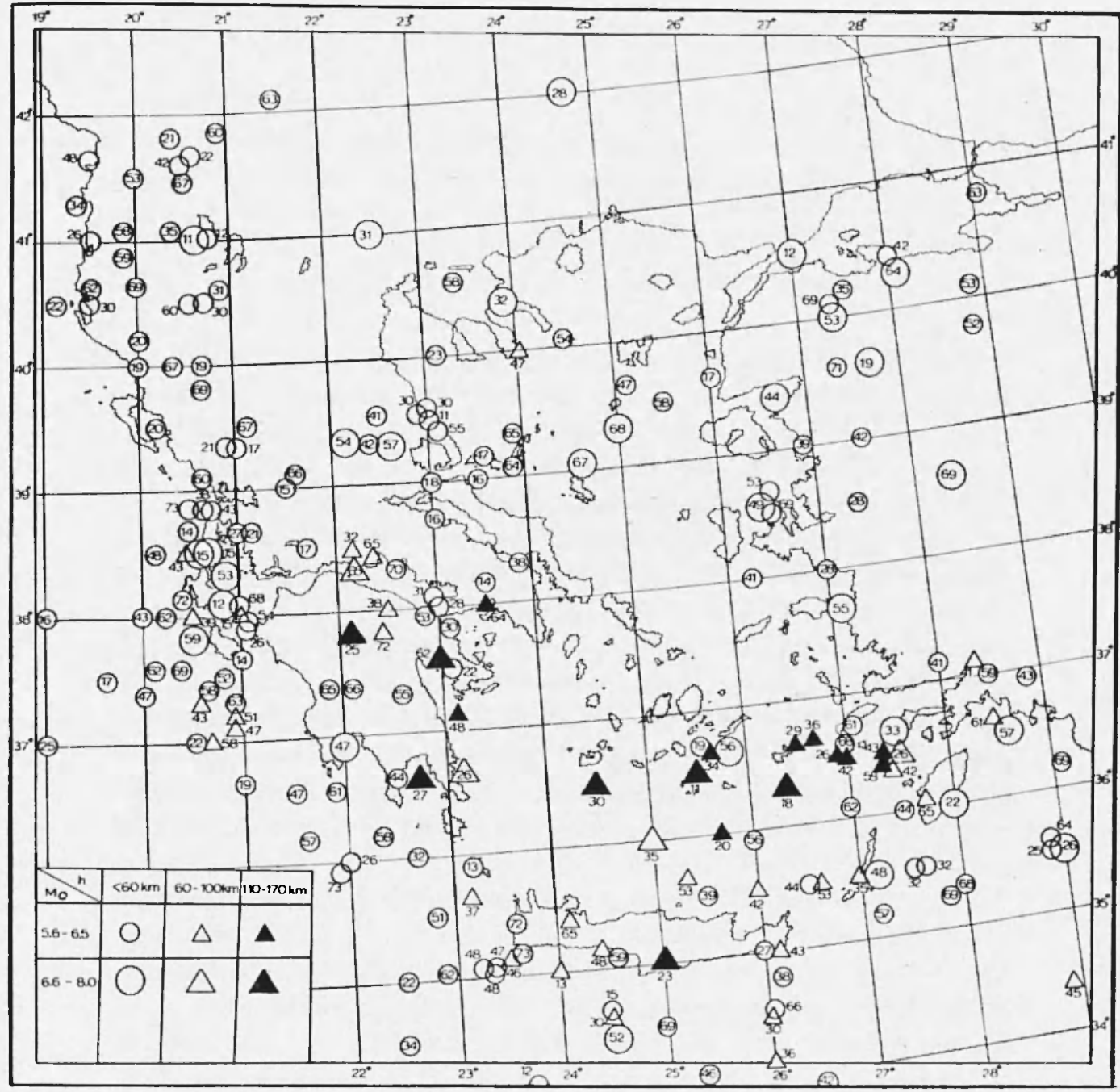

Fig. ] - Index map of the location of all main shocks which oceurred in the area of Greece between 1911 and 1973 and had $\Psi_{0} \geqslant 5.6$. 
between 1911 and 1973. Six symbols have been used to denote two magnitude ranges and three ranges of focal depths. The numbers in or close to each symbol are the last two numbers of the year of occurrence.

TIIE TLME DISTRHBLTION OF APTERSIIOCKS AND FORESHOCK

It has been shown by several seismologists that the number, $n(t)$, of aftershocks of a sequence per time unit is given by the relation

$$
n(t)=n_{1} t \cdot p
$$

where $t$ is the time measured from the origin time of the main shock, $n_{1}$ is the frequency of shocks one time unit after the origin time of the main shock and $p$ the decay parameter. Relation [1] is valid for complete sets of data, that is, for sequences which include all earthquakes with magnitudes above certain magnitude threshold.

The parameter $n_{1}$ depends on the magnitude threshold, which varies from sequence to sequence, but accorling to Gibowicz $\left(^{3}\right)$ its reduced value to the same magniturle level depends on the fanlt area and the stress rlop in the focal region. The valnes of the lecay parameter $p$ are frequently a little larger than 1 but values between 0,9 and 1.9 have been reported by several authors $\left({ }^{16.20}\right)$. Evidence has been presented by Mogri $\left(^{4}\right)$ that this parameter depends on some physical conditions in the focal region. He has observed a consistent geographical distribution of the values of this parameter in the area of Japan.

No much quantitative work has been done on the time variation of the frequency of foreshocks. This is due to the lack of sufficient data. The present author ( $\left.{ }^{8}\right)$ has shown that the time dependence of the frequency of foreshocks of four earthquakes believer to be associated with artificial lakes can be rescribed by the relation $n(t)=n_{0}(\tau-t)^{t}$, where $n(t)$ is the number of foreshocks per time unit, $t$ is the time measured from the time $t_{0}$ at which $n(t)=1$, and $n_{0}, \tau, h$ are parameters. 
THE VALIDI'Y OF TILE TIME LAW FOR AFTERSIIOCK'S IN TILE AREA OF GREECE

Ranalli $\left({ }^{16}\right)$ has concluder that the time ristribution of the aftershocks of some sequences in the area of Greece show some departure from the statistical law which is described by [1], because he has found that in these cases a consirlerable percentage of the observations are out of the ninety five per cent confidence intervals. He has attributerl it to some geotectonic reasons and partly to poor lata, since these data have been received by old instruments.

One of the reasons for this anomaly is that the rata used by Ranalli are not complete below certain magnitude threshold in some cases. Therefore, we can decrease the number of the observations which are outsirle of the ninety five per cent confidence intervals by considering only the earthquakes with magniturles above this threshold.

Papazachos ( $\left.{ }^{9}\right)$ has grouper the data of 37 complete aftershock sequences in this area and found that all points are well within the ninety five per cent confirlence intervals. This shows that the time ristribution law holds, in general, in this area. It is, however, possible that individual aftershock sequences are multiple sequences similar to those observerl by Utsu (21) in Japan where the geotectonic conditions are similar to those in Greece. Such phenomena are sometimes observed in this area and can explain the departure from the law at least partly.

We have found that even if some points are outside of the ninety five per cent confidence intervals, whenever the grouping has been made in the way suggested by Utsu (19) and Ranalli $\left({ }^{16}\right)$, we can still determine a reliable value of $p$ in many cases, by changing slightly the methor of grouping. By putting the requirement that each frequency value must be calculated by a number of shocks larger than a cergtain value $n$ (e.g. $n=3$ ), we can have the data even fully satisfying the statistical criterion. This can be done by considering two or more neihbouring time intervals as one and by making the proper calculations of the frequency and of the corresponding time.

\section{REPRESENTATIVE VALUES OF $p$ AND $h$ FOR TIL AREA OF GREECE}

Papazachos $\left({ }^{9}\right)$ has proposed a way of grouping the data of several aftershock sequences in a region to determine a representative value of 
$p$ for this region. He has applied this method to the rata of 37 aftershock sequences for which the number of aftershocks is larger than $\mathbf{1 6}$ to rletermine a representative value of this parameter for the area of Greece. Tts value has been found equal to 1.13 with 1.08 and 1.18 ninety five per cent confidence intervals.

By the same methor it has been found $\left({ }^{9}\right)$ that the ordinary foreshock sequences follow a statistical law of the form:

$$
n(t)=n_{1}\left(\tau_{0}-t\right)^{-n}
$$

where $n(t)$ is the number of foreshocks per day, $t$ is the time measured from the time $t_{0}$ for which $n(t)=1, \tau_{0}$ is the time between $t_{0}$ and the origin time of the main shock, and $n_{1}$ and $h$ two other parameters. By the use of the existing rlata for all the complete sets of foreshocks in the area of Greece a value for $h$ equal to 1.34 with 1.08 and 1.60 ninety five per cent confidence intervals has been found.

\section{DEPExDExCE OF $p$ ON THE MAGNITUDE RANGE}

It is usually assumed that the value of the decay parameter $p$ is constant for each sequence, that is, independent of the minimum magniturle threshold $M_{s}$ chosen for counting the frequency of aftershocks. This assumption is very important because if it is not valid the $p$ values determinerl for different aftershock sequences camnot be compared.

In order to confirm or reject the valirlity of this assumption we have used the existing lata of the aftershock sequence of an earthquake of magnitude $M=6.3$ which occurred on February 5, 1966, near the Kremasta artificial lake and which is believed to be associated with the water impounding in this lake $(1,8)$. We have used these data because in this case a very large number of aftershocks has been recorded by modern instruments.

Figure 2 shows the time distribution of the aftershocks of the Kremasta earthquake for three minima magnitude thresholds. The dots, tringles and open circles show the time ristribution of the aftershocks which occurred within 100 days after the main shock and had magnitudes $M_{L} \geqslant 2.3, M_{L} \geqslant 2.9$ and $M_{L} \geqslant 3.5$, respectively. The corresponding numbers of the aftershocks are 1918, 426, 94 and the values of $p$ rletermined by the least squares method are $0.68,0.71,0.72$. 


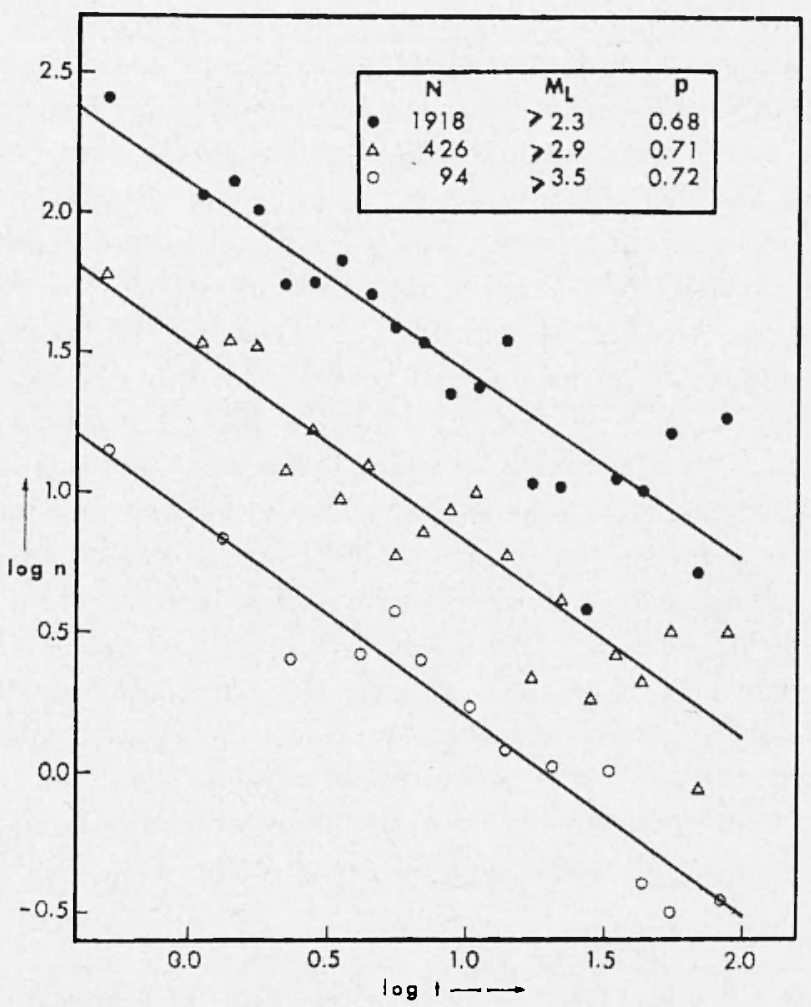

Fig. 2 - The time distribution of aftershocks of the Kremasta earthquake for three minima magnitude thresholds. The corresponding values of the total number of aftershocks, $N$, and those of the decay parameter, $p$, are also shown.

To group the clata in the first two cases ( $N=1918, N=426$ ) the method mentioned above $\left({ }^{16,19}\right)$ has been applied except that the frequency of aftershocks of the first day has been also counted since we found no reason to reject the data of the first day in the present case. In the last case $(N=94)$ the same method of grouping has been also applied but when the number of shocks in a time interval was smaller than 3 two neighbouring intervals were considered as one and the proper calculations of the frequency and of the corresponding time were marle.

It can be observed that the magnitude range has essentially no effect on the calculated value of the parameter $p$. Utsu $\left({ }^{20}\right)$ has arrived at the same conclusion. 
In a previous paper ( ${ }^{1}$ ) a value equal to 0.78 has been foumd for the parameter $p$ of the Kremasta aftershock sequence. The difierence between this value and the value deternined in the present paper is partly due to the difierent methods of grouping the data. The methorl of grouping used in the present work has some alvantages over the method used to determine the value 0.78 . On the other hand the value 0.70 has been determined in the present work by the use of the data of the first one humbled days after the occurrence of the main shock while the value 0.78 has been determined by the data of a longer period.

The value 0.70 is one of the lowest values of $p$ observeal so far.

It is much smaller than 1.13 which is the most representative value for the area of Greece and lower than all values of this parameter determined in the present paper for six ordinary aftershock sequences in this area. For the aftershock sequences in Japan the value of $p$ falls in the range between 0.9 and 1.9 but values between 1.0 and 1.4 are most frequent. The low value of $p$ for the aftershock sequence of the Kremasta earthquake is probably dne to its association with the Kremasta artificial lake. There is additional evidence that the time distribution of the aftershocks of the earthquakes which are associated with artificial lakes are characterized by low $p$ values $\left({ }^{10}\right)$.

\section{THE RAXGE OF VARIATION OF $p$ IN TIIE AREA OF GREECE}

In order to get an idlea about the range of variation of the decay parameter $p$ in the area of Greece, values of this parameter have been determined for the aftershock sequences of the main shocks for which the number of the listerl aftershocks is larger than 100. There are six such sequences. The time distribution of these six sequences is shown in figure 3 . The corle Number, $N_{0}$, in the tables I and II of the publication $\left({ }^{12}\right)$, the total number, $N$, of aftershocks, the minimum magniturle threshold, and the determined, by the least squares methor, value of the decay parameter $p$ are also shown in this figure. The method of grouping is that applied for the Kresmata aftershock sequence.

It can be observerl that the values of $p$ range between 0.83 and 1.86. Their mean value is equal to 1.12 which is almost iclentical with the value based on the data of 37 aftershock sequences of this area (9). The largest value of $p$ has been found for the aftershock sequence of the big earthquake ( $M=7.5$ ), which occurred on July 6 , 1956 in the volcanic part of the Hellenic are. 

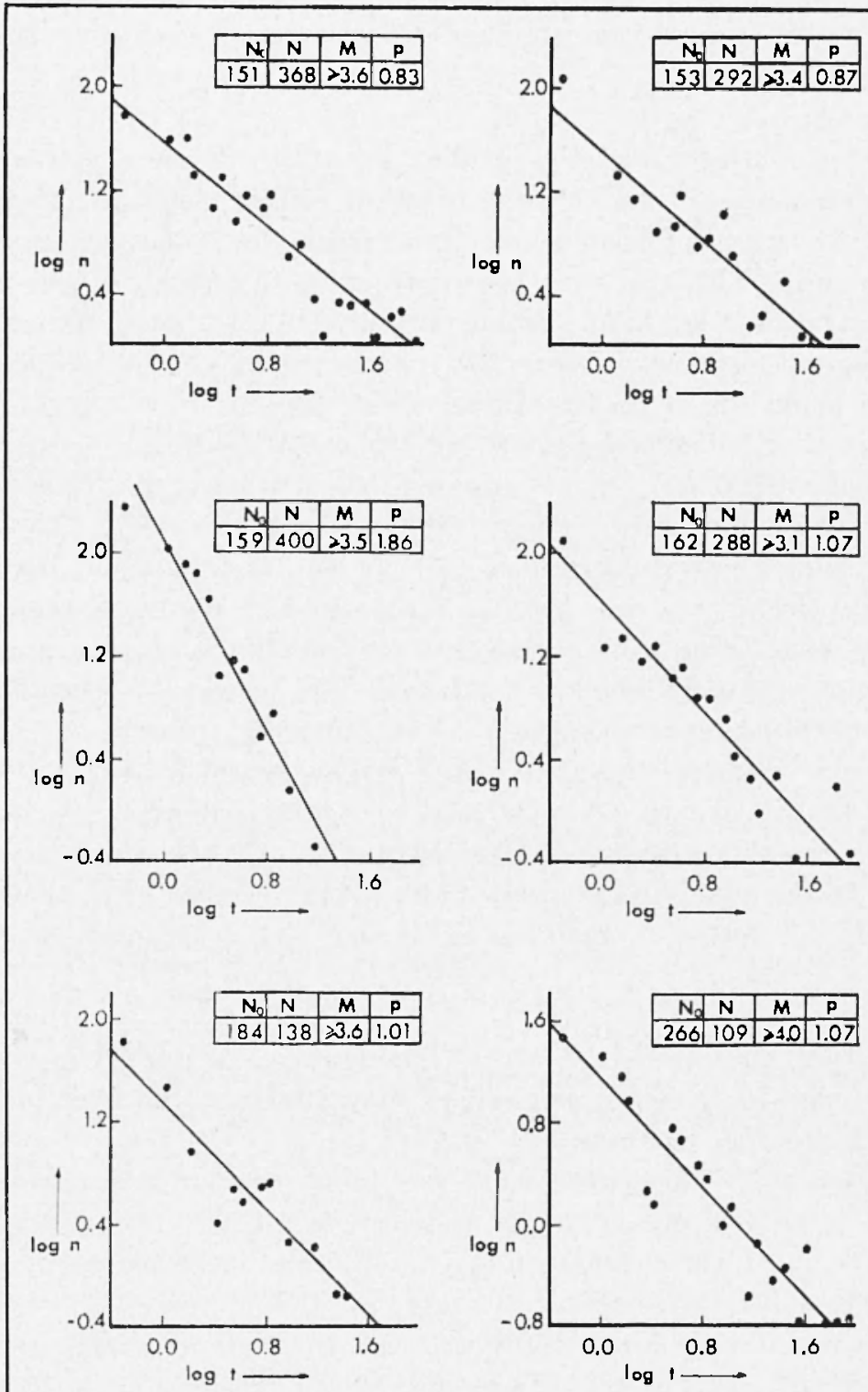

Fig. 3 - The time distribution of aftershocks of six secuenees in Greece. The colle number, $x_{0}$, of ach sequenee in table II of the publication $\left({ }^{12}\right)$, the total number, $X$, of aftershocks, the minimum earthquake magnitute, and the value of the decay parameter $p$ are also shown. 
TIMES OF OCCURRENCE OF THE LARGEST AFTERSHOCK AND OF THE LARGEST FORESIIOCK

The statistical forecasting of the time of occurrence of the largest aftershock is of theoretical and practical significance. When these shocks are large and occur in inhabited areas, they cause considerable damage since the structures have alrealy been shaken by the main shock. On the other hand statistical results on the time of occurrence of the largest foreshock in respect to the main shock can be usen to give an irlea about the origin time of the main shock.

The time difference $T_{1}$ between the main shock and the largest aftershock varies from a few minutes to a few months. To investigate the distribution of $T_{1}$ only the largest aftershocks of the main shocks which have magnitudes $M_{0} \geqslant 6.0$ and occurred between 1911 and 1973 in this area have been considered. We have taken into account only those shocks because the probability of observational uncertainties is very small in these cases and because only the aftershocks of this lange of magnitude can be damaging. This investigation has shown that the cumulative distribution function of $T_{1}$ is more satisfactorily fitted by a simple relation than the frequency function.

Figure 4 shows the cumulative distribution of the relative frequency of $T_{1}$. In this plot, $N$ is the probability that the largest aftershock will occur $T_{1}$ days after the main shock or later. $A$ relation of the form

$$
N\left(T_{1}\right)=c-k \log T_{1}
$$

fits well the data as it is shown in this figure. When $T_{1}$ is measured in days the values of the parameters, determined by the least squares method, are $e=0.53$ and $k=0.23$.

Relation [3] and figure 4 show that in 47 per cent of the cases the largest aftershock occurs in the first day, in 70 per cent in the first ten days, in 81 per cent in the first month, and in 88 per cent in the first two months after the main shock.

Papazachos (11) has investigated the time of occurrence of the largest foreshocks which have precerled the main shocks with $M_{0} \geqslant 6.0$ in the area of Greece. A relation of the form [3] gives the probability that the largest foreshock will occur $T_{1}$ days before the main shock or sooner, with $e=0.59$ and $k=0.31$. The similarity between the two relations which describe the time rlistributions of the largest foreshocks and the largest aftershocks is surprising. 


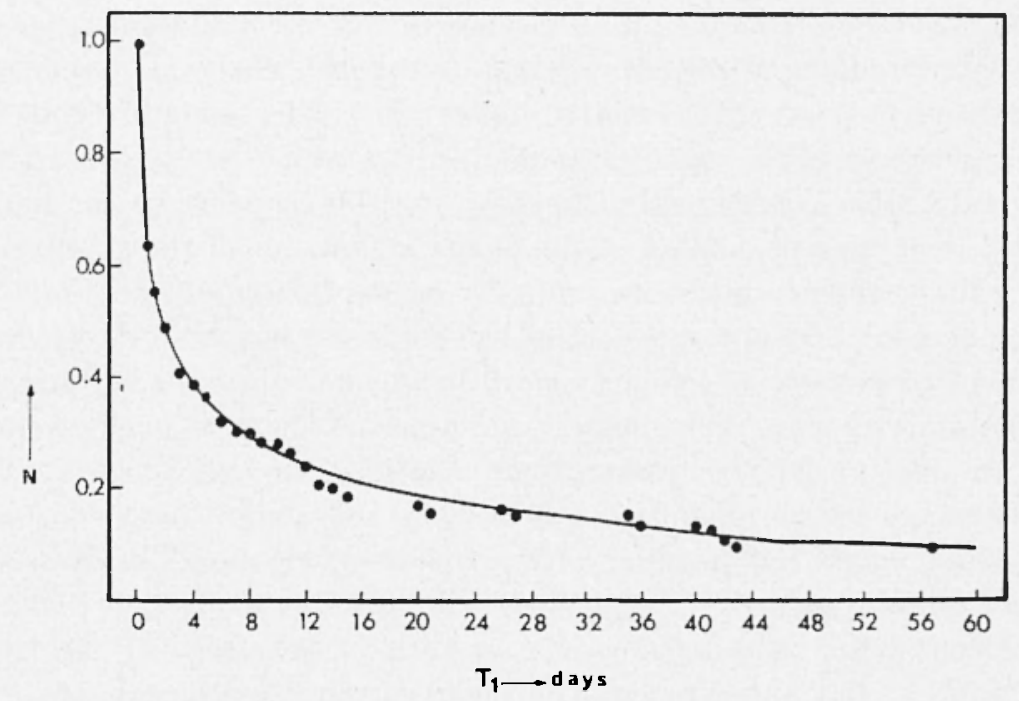

Fig. 4 - The cumulative frequency distribution of the difference between the times of occurrence of the main shock and the largest aftershock.

The Magytude DistRIBUTION LAW AND ITS VALIDITy IN THE AREA OF Greece

One of the most important statistical laws in Seismology is the well known relation between the frequency $n$ and the magnitude $M$ of the earthquakes, which occur in a certain region and within a certain period of time. Most seismologists tolay calculate the cumulative distribution $N$ because the errors in the magnitures are smootherl out. Then the law is expressed by the relation:

$$
\log N=a-b M
$$

where $N$ is the number of shocks with magnitude equal to or larger than $M$ and $a, b$ are parameters. This relation, also, holds for seismic sequences. The parameter $b$ is very important as it has some association with several important problems such as the stress and other conditions in the focal regions $\left(^{5,17}\right)$ and the earthquake prentiction problem $\left({ }^{23}\right)$.

Ranalli ( ${ }^{16}$ ) has investigater statistically the magnitude distribution of the earthquakes of six seismic sequences in the area of Greece. He 
has applied Utsu's method and has found that in some cases a considerable percentage of the points in the recurrence curve are outside of the ninety five per cent confilence intervals. This is mainly true for the aftershocks of the earthquake of Karditsa which has corle number 153 in the table I of the publication (12). For this sequence he has found that a very large percentage of the points are outside of the ninety five per cent confidence intervals. On the basis of these observations he has conchurled that in these cases either the law is not valid or the data are poor since they are taken by old instruments. Both his conclusions are only partly true. The anomaly is due to the fact that in these cases the cumulative frequency-magnitucle relations are not linear in the whole range of the magnitures he used to determine these relations.

Real partial non-linearity of the frequency relation has been observer in many cases $\left({ }^{6,13,14,22}\right)$. This is mainly due to the fact that the recurrence curve is usually convex upward in the range of the large magniturles, but this property of the recurrence curve can be only partly responsible for the observed anomaly. The non-completeness of the publisherl data in the range of low magnitudes is the main reason why a consirlerable percentage of the points are outsirle of the confirlence intervals. To give an example we will examine the aftershock sequence of the Karditsa earthquake $\left[\mathrm{N}_{0}=153\right.$ in table $\mathrm{I}$ of publication (12)]. For this sequence, Ranalli has used all the data which cover the magnitudes between 3.2 and 5.9 and found that $b=0.64$ and that $58.3 \%$ of the points are outside of the ninety five per cent confidence intervals. An inspection of the plot of the data shows that this sequence can be considererl complete for magniturles larger than or equal to 3.6. The application of the methorl user by Ranalli to the data which concern the magnitude range between 3.6 and 5.9 gives very different results. Figure 5 shows the cumulative distribution for this range of magnitudes. The rashed lines show the $95 \%$ confirlence intervals. Utsu's methor give now $b=1.0$. Only one point out of 18 is outsirle of the dasherd lines which means that only $5.6 \%$ of the points are outside of the $95 \%$ confirlence intervals now. This small deviation can probably be attributed to uncertainties in the data. It is worth noted that the $b$ value for this sequence, determined by the least squares method $\left(^{6}\right)$, is also equal to 1.0 .

The criterion put by Ranalli $\left({ }^{16}\right)$ has been applied to many complete sequences in this area. It has been found that the percentage of the observations which are outside of the ninety five percent confirence intervals is in most of the cases equal to zero and in the other 
cases is usually small. Therefore we can conclude that the frequencymagnitude law holds for the seismic sequences in the area of Greece.

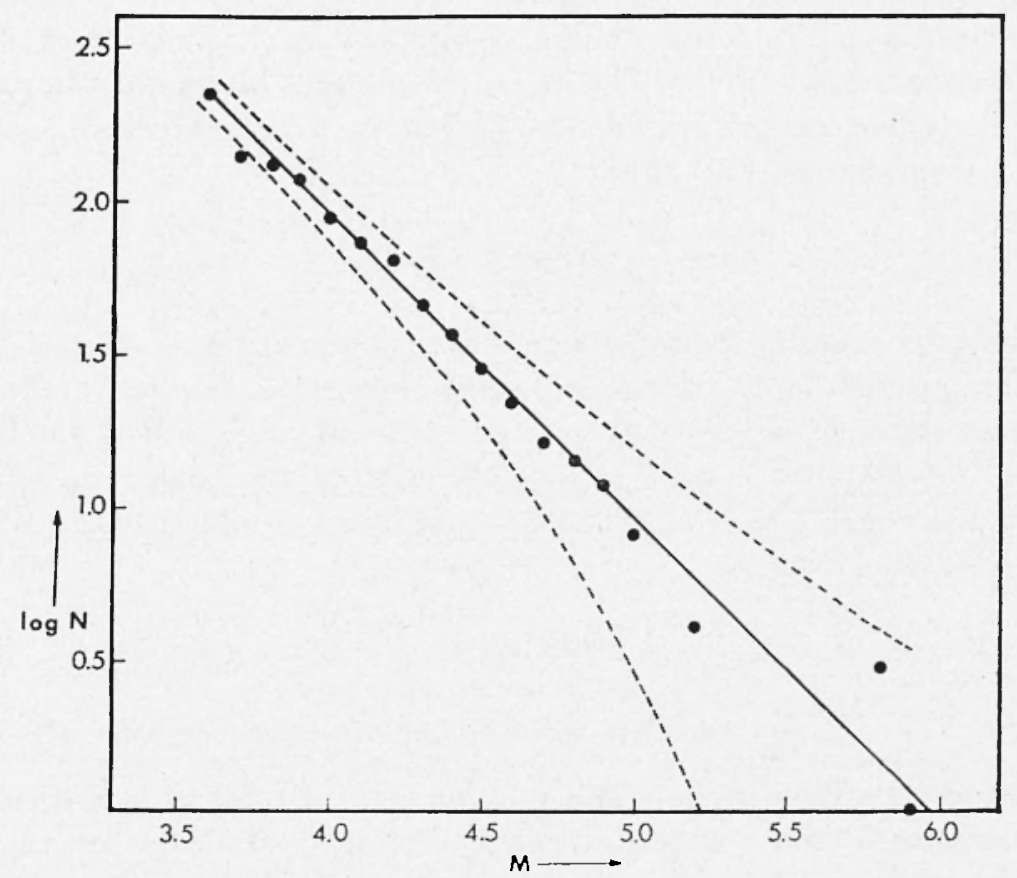

Fig. 5 - The magnitude distribution of aftershocks of the Karditsa earthquake of April $30,1954$.

TIIE PARAMETER $b$ FOR FORESHOCKS AND FOR THE CORRESPONDIYG AFTERSHOCKS

The parameter $b$ for foreshock sequences is of great importance in Seismology because its small value in relation to the value of this parameter for aftershock sequences and background seismic activity can be considered as a precursor of the main shock $(11,18)$. However, some seismologists do not fully agree that the value of foreshock $b$ is always smaller than the value of the corresponding aftershock $b$. This disagreement is mainly due to the fact that it is difficult to determine this parameter with accuracy since the number of foreshocks is 
usually small. For this reason it is probably preferable to determine a representative value of the foreshock $b$ in a region, by properly grouping all the foreshock data, and compare this value with the representative value of $b$ of the corresponding aftershocks. In the following a method of gromping is suggested and applied to find such values of $b$ for the foreshocks and the corresponding aftershocks in the area of Greece.

Let us assume that we know the magnitudes of several complete seismic sequences in a region. The cumulative frequency function for the $i$ sequence can be written.

$$
N_{i}=10^{m u t}
$$

where $m$ is equal to the difference between the magnitude $M$ and the largest magniturle $M_{1}$ in the sequence, that is $m=M_{1}-M, N_{i}$ is the number of earthquakes for which the difference is $m$ or smaller. If we replace each $b_{i}$ by $b$ so that the sum of the second members should be equal to the sum of the first members and take the logarithms of both sums we find

$$
\log N=b m
$$

where $N=\sum_{1}^{k} \frac{N_{t}}{k_{i}}$ and $k$ is the number of sequences with $M_{1}-M$ equal to or larger than $m$. This relation gives a value of $b$ which can be considered as a representative value of this parameter for all sequences.

There are $4 \tau$ foreshocks sequences in the table II of the publication (12) with two or more foreshocks. These data and the data for 14. foreshock sequences of small earthquakes with epicenters not far from Athens published by Drakopoulos $\left({ }^{2}\right)$ have been used to determine b. These 61 foreshock sequences include 290 foreshocks for which $M_{1}-M \leqslant 1.5$. The same procedure has been followed for the aftershock sequences which belong to the same main shocks with the 61 foreshock sequences. These aftershock sequences include 790 aftershocks with $M_{1}-M \leqslant 1.5$. Figure 6 shows the $\log N$ versus $M_{1}-M$ for foreshocks and aftershocks. It is clear that the $b$ value for foreshocks is smaller than the $b$ value for aftershocks. The two straight lines which lit the data have been determined by the generalized least squares method. Each value of $\log N$ has been weighterl according to the value of $h$. The value of $b$ for foreshocks has been found equal to 0.67 and for the corresponding aftershocks equal to 0.92 . 


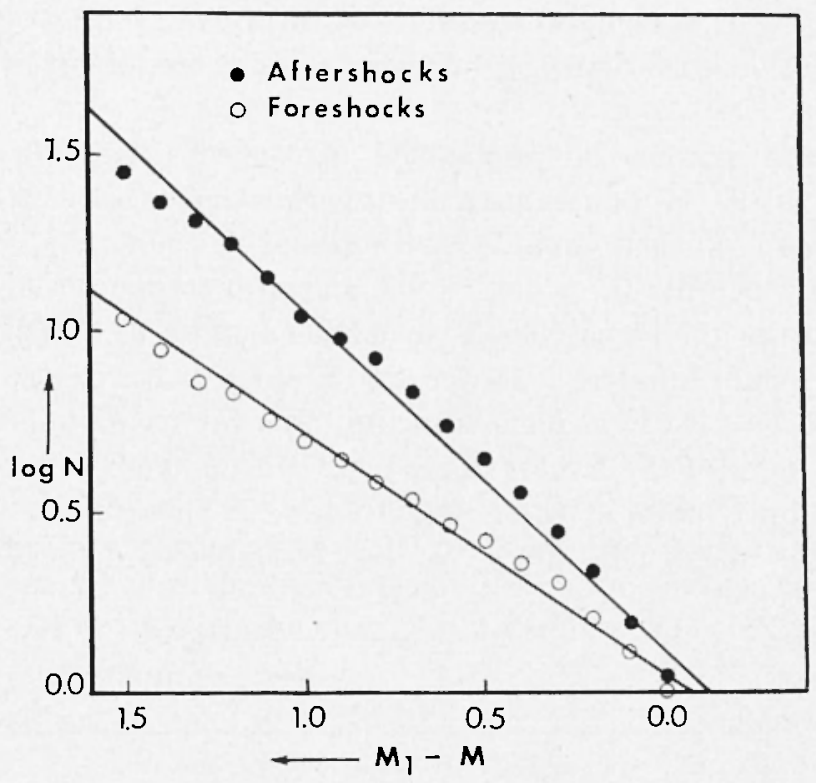

Fig. 6 - The magnitude distribution of the foreshocks and of the corresponding aftershocks.

\section{MAGNITUDES OF THE LARGEST AFTERSHOCK AND OF TIE LARGEST FORESHOCK}

Several attempts lave been male to determine statistical relations between the magnitude, $M_{0}$, of the main shock and the magnitucle, $M_{1}$, of the largest aftershock. Accoring to Bath the relation $M_{0}-M_{1}=1.2$ holds. Utsu (20) has found the relation $M_{0}-M_{1}=$ $5.0-0.5 \Lambda_{0}$ for earthquakes in Japan.

To find such a relation the data must be complete. In other words it is necessary to determine the magnitudes of the largest aftershocks of all the main shocks which have magnitules larger than a certain value and have occurred in a certain region and within a certain period of time. The largest aftershocks of all, but two, the main shocks with $M_{0} \geqslant \mathbf{6 . 0}$ which are listen in the table II of the publication ( $\left.{ }^{2}\right)$, fulfill this condition. In other words we know the magniturles of the largest aftershocks of all the main shallow shocks with $M_{0} \geqslant 6.0$ which occurred 
in the area of Greece between 1911 and 1973 except for two cases in which only the upper limits of the magniturles of the largest aftershocks are known.

The total number of the shallow main shocks with $M_{0} \geqslant 6.0$ in that table is 89 . If we assume a linear correlation between $M_{0}$ and $M_{1}$ a correlation coefficient equal to 0.50 is found by these rlata. The slope of the line which fits these data is not much different from unit, which means that the diflerence $M_{0}-M_{1}$ is independent of $\boldsymbol{I}_{0}$. This difference has been found equal to 1.13 for the 89 ases with $M_{0} \geqslant 6.0$.

For 23 out of 219 sequences in the table II of the publication ${ }^{(2)}$, the magnitules of the largest aftershocks are not known but only the probable upper limits of these magnitudes. If these upper limits are taken as the magniturles of the largerst aftershocks in these 23 cases,

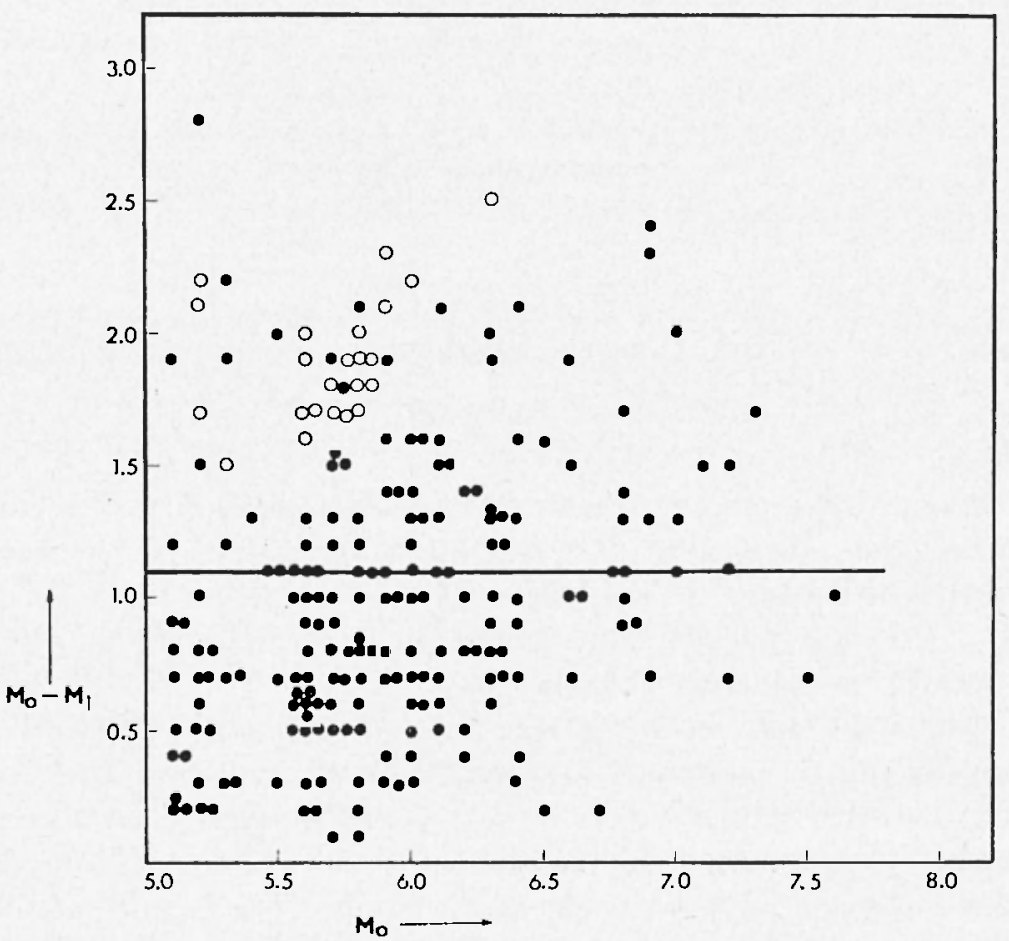

Fig. 7 - Plot of the difference in magnitude between the main shock and the largest aftershock versus the magnitude of the main shock. 
the relation $M_{0}-M_{1}=-1.07$ will be found to hold for the 219 sequences in this area. We can therefore safely conclude that the relation:

$$
M_{0}-M_{1}=1.1
$$

holds for the mean difference between the magnitude of the main shock and the magnitude of the largest aftershock in the area of Greece, at least when $M_{0} \geqslant 5.1$. This relation is almost identical with Bath's relation.

Figure 7 shows the plot of $M_{0}-M_{1}$ versus $M_{0}$. The lots show the cases for which the magnitudes of the largest aftershocks are known and the open circles the cases for which the magnitudes of the largest aftershocks are assumed to be equal to their probable upper limits. The large scattering shows that the value of $M_{1}$ depends on other parameters too. Purcaru ${ }^{(5)}$ ) has shown that the difference $M_{0}-M_{1}$ is a linear function of the parameter $b$.

The author of the paper (11) has used the homogeneous data for 39 recent foreshock sequences of main shocks with $\boldsymbol{M}_{0} \geqslant 5.5$ and has found a linear correlation between the magnitude $M_{-1}$ of the largest foreshock and the magnitude of the main shock, with a correlation coefficient equal to 0.54 . The slope of the regression line has been found almost equal to one. The relation:

$$
M_{0}-M_{-1}=1.9
$$

holds on an average.

Relations [7] and [8] and the finding that the $b$ value for foreshocks is smaller than the $b$ value for aftershocks fully justify the observation that the number of foreshocks is usually much smaller than the number of aftershocks of a main shock.

\section{REFERENCES}

(1) Compinakis P., Drakopoulos J., Moumoulimis G., Papazachos B. C., 1968. - Foreshock and aftershock sequences of the Kremasta earthquatie and their relation to the vaterloading of the Kremasta artificial lake. "Annali di Geof.", XXI, pp. 39-7I.

${ }^{2}{ }^{2}$ Drakopoulos J., 1968. - Characteristic paramelers of fore-and aflershock sequences in the area of Cireece. "Sci. D. Thesis, Univ. Athens", pp. 1-130. 
(3) Grbowicz S. J., 1973. - Stress drop and aftershocks. "Bull. Seism. Soc. Ailı.", 63, pp. 1433-1446.

(1) Moa $\mathrm{K} ., 1962$. - On the time distribution of aftershocks accompanying the recent major earthquakes in and near Japan. "Bull. Earthq. Res. Instit.", 40, pp. $107-124$.

(5) Mogi K., 1963. - The practure of a semi-infinite body caused by an inner stress and its relation to earthqualie phenomena (second paper). "Bull. Earthq. Res. Instit.", 41, pp. 595-614.

(6) Papazacios B. C., Delibasis N., Liapis N., Moumoulidis G., and Purcaru G., 1967. - Aftershock sequences of some large earthquakes in the region of Greece. "Annali di Geof.", XX pp. 1-93.

(7) PAPAZACIOS B. C., 1971. - Aftershock activity and aftershock risk in the area of (rreece. "Annali di G.cof.", XXIV, pp. 439-456.

(8) Papazacios B. C., 1973. - The time distribution of the reservoir-associated foreshocks and its importanee to the prediction of the principal shock. "Bull. Seismol. Soc. AnI.", 63, pp. 1973-1978.

(9) Papazachos B. C., 1974. - On the time distribution of aftershocls and foreshocks in the area of Greece. "Pure and Appl. Geophys.", 112, pp. 627-631.

(10) Papazaciros B. C., 1974. - On the relation between certain artificial lakes and the associated seismic sequences. "Engineering Geology", 8, pp. $39-48$.

(11) Papazachos B. C., 1974. - Foreshocks and earthquake prediction. "Tectonophysies", in press.

${ }^{\left({ }^{12}\right)}$ Papazacios B. C., 1975. - Attershock and foreshock sequences in the area of Greece during the period 1911-1973. "Bull. Scient. Gr. Space Res.", 3, pp. 1-36.

(13) Papazacios B. C., 1975. - Dependence of the seismic parameter $b$ on the magnitude range. "Pure and Appl. Geophys.", (in press.).

(14) Procinazkova D., 1970. - Analysis of methods of caleulating the magnitude - frequency relation. "Travaux de l'Institute Géphysique de l'Acádemie Tećcoslovaque des Sciences", 325, pp. 229-255.

(15) Purcaru G., 1974. - On the statistical interpretation of Bath's law and some relations in aftershock statistics. "Geol. Inst. Technic. and Econ. Stud., Geophys. Prosp., Bucharest”, 10, pp. 35-84.

$\left({ }^{16}\right)$ RaNaldi G., 1969. - A slatistical study of aftershock sequences. "Annali di Geof.", XXII, pp. 359-397.

(17) Scmouz C. H., 1968. - The frequency-magnitude relation of microfracturing in rock and its relation to earthquakes. "Bull. Seism. Soc. Am.", 58, pp. $399-415$.

$\left({ }^{18}\right)$ Suyenino S., 1966. - Difference between aftershocks and foreshocks in the relationship of magnitude to frequency of occurrence for the great Chilean earthquake of 1960. "Bull. Seism. Soc. An.", 56, pp. 185-200.

(19) Ursu T., 1962. - On the nature of three Alaskan aftershock sequences of 1957, and 1958. "Bull. Seism. Soc. Am.", 52, pp. 279-297. 
$\left.{ }^{(20}\right)$ Utsu T., 1969. - Aftershocks and earthquake statistics (I). "Jour. Faculty Science, Hokkaido Univ.", 3, pp. 129-195.

(21) UTsu T., 1970. - Aftershocks and earthqualie statisties (II). "Jour. Faculty Science, Hokkaido Univ.", 3, pp. 197-266.

(22) UTsU T., 1971. - Aftershocks and earthquake statisties (III). "Jour. Faculty Science, Hokkaido Lnir.", 5, pp. 379-441.

(23) WYSS M. and Les W. H. K., 1973. - The variation of the acerage earthguake magnitude in central Califormia. "Proceedings on the Conference on Tectonic Problems of the San Andreas Fault System", ed. R. Kovach and A. Nur, 130, pp. $24-42$. 